ISSN: 0213-2087 e-ISSN: 2444-7080

DOI: https://doi.org/10.14201/shhcont382020129150

\title{
ENTRE EL COLORÍN Y EL COLOR. LAS FALLAS DE LA VICTORIA Y LA NACIÓN VIRIL DE POSGUERRA
}

\author{
Between the blaze and the color. The Fallas de la \\ Victoria and the virile nation of the early Francoism
}

\author{
Zira $\mathrm{BOX}^{1}$ \\ Universitat de València
}

Recibido: 15/04/2020 Revisado: 04/07/2020 Aceptado: 14/07/2020

RESUMEN: El presente artículo parte de la consideración de que, a lo largo de la inmediata posguerra, el discurso sobre la nación se articuló a partir de la asunción de que la nueva España que había vencido en la guerra civil era intrínsecamente viril. Mostrando fuertes continuidades con el discurso regeneracionista previo, la noción de virilidad —una noción suficientemente transversal a las diferentes culturas políticas franquistas- se articuló a partir de atributos que hablaban de fuerza, vigor e ímpetu, a la par que de sobriedad, compostura y control. A cambio, funcionando de antítesis, el peligro del afeminamiento implicaba, tanto una versión de la nación carente del impulso propio de la virilidad como una distorsión por exceso que desembocaba en una versión histriónica, chabacana y bufa. Partiendo de lo anterior, el artículo se centra de forma concreta en el discurso desarrollado en torno a la celebración de las primeras Fallas de posguerra, las festejadas en marzo de 1940, considerando que se trató de una fiesta ambigua, por localista y bullanguera, que necesitó de una depuración narrativa destinada a virilizarla. El análisis de dicho discurso, así como sus límites y alcances, es el objetivo principal de este texto.

Palabras clave: Fallas; franquismo; virilidad; nación; afeminamiento; género y nación.

ABSTRACT: Throughout the immediate postwar period, the discourse on the nation was articulated around the assumption that the new Spain was inherently virile. Showing clear continuities with the previous regeneracionismo, the notion of virility, which was

1. La autora participa en el proyecto «Derechas y nación en época contemporánea. Una perspectiva transnacional» (PGC2018-099956-B-I0). 
crosscutting enough to the different political cultures that conformed the regime, was constructed with two kind of attributes: those which alluded to force, vigor and impetus, and those which referred to sobriety, composure and control. In exchange, working as the opposite, the danger of effeminacy supposed both the version of the nation lacking the impulse typical of virility as well as the distortion in excess that resulted in a tasteless, gaudy and histrionic version. Taking the previous argument as a point of departure, the article is focused specifically on the discourse developed around the first celebration of the valencian Fallas after the end of the civil war, the one which took place on March 1940. Considering that it was an ambiguous celebration due to its local taste and rowdy character, the hypothesis of the text is that it needed to be reformulated in order to fit into the main discourse of national virility. The analysis of this discourse, as well as its limits and achievements, constitute the main goal of this article.

Key words: Fallas; Francoism; virility; nation; effeminacy; nation \& gender.

A finales de octubre de 1939, la Presidencia de la Comisión de Fiestas de la ciudad de Valencia solicitaba al Ayuntamiento la autorización necesaria para poder comenzar con los preparativos de las festividades falleras programadas para el mes de marzo de $1940^{2}$. Tras los años de guerra en los que el bando franquista había permanecido fuera de la ciudad y en los que se había tenido que recurrir a plantar una simbólica Falla en la nacional ciudad de Toledo ${ }^{3}$, las próximas fiestas se imaginaban como las resurgentes Fallas de la Victoria ${ }^{4}$. Con ello, los responsables políticos de la ciudad pretendían retomar uno de sus ritos más queridos, emparentado desde sus orígenes con las celebraciones en honor de San José, convertido progresivamente en fiesta mayor a partir de finales del siglo XIX y transformado en símbolo de la identidad valenciana así como en notable atracción turística desde los años de anteguerra ${ }^{5}$. Junto a lo anterior, y como no podía ser menos, con la mencionada resurrección la intención del nuevo régimen también era convertir la celebración en una festividad que estuviese a tono con los valores que impregnaban la nueva España franquista.

Desde muy temprano, comenzó lo que Gil-Manuel Hernàndez denominó en su exhaustiva monografía el periodo de reconstrucción y totalización de la fiesta: reconstrucción por cuanto que se creó un entramado institucional destinado a controlarla, encabezado por la Junta Central Fallera en tanto institución englobadora del conjunto

2. Reunión de la Presidencia de la Comisión de Fiestas celebrada el 23 de octubre de 1939. Archivo Histórico Municipal de València (AHM), Caja 63.

3. En 1937 se plantaron cuatro Fallas en la ciudad de València que estaba bajo dominio republicano. Están explicadas en "L'enemic del poble a l'infern" de la revista Nueva Cultura, en la que participó el propio Josep Renau, entonces director general de Bellas Artes del gobierno republicano, con un texto. El bando franquista plantó una Falla en Toledo. Está explicada en Julià MARTínez, Eduardo: Una Falla en Toledo en 1937. Valencia: Imprenta Hijo de F. Vives, 1943. Un análisis de ambas, en PANEA, Linda: «Les Falles i la guerra civil», Revista d'Estudis Fallers, 10, 2005, pp. 51-70.

4. "Resurrección de la típica fiesta», Fallas 1940, marzo de 1940.

5. Para una detallada historia y evolución de las Fallas, ver la segunda parte de ARIÑo, Antonio: $L a$ ciudad ritual. La fiesta de las Fallas. Barcelona: Anthropos, 1992. 
de las Comisiones de Fallas ${ }^{6}$; y totalización, por la explícita intención de resignificar la festividad y de eliminar sus posibles elementos trasgresores, insertándola dentro de los férreos parámetros ideológicos de la dictadura ${ }^{7}$.

Dejaba claro esto último Martín Domínguez, presidente de la Comisión de Festejos del consistorio valenciano, en el mensaje radiado que se emitía el 9 de diciembre de 1939. Recurriendo a una gráfica metáfora vegetal, señalaba que enfrentarse a esa cosa tremenda que eran las Fallas era similar al hecho de mirar un campo fértil, pero descuidado. Existía, sí, un verde caudal de plantas fructíferas y aprovechables, pero ahogadas por otra vegetación, tan exuberante como dañina, que sofocaba y mataba a los tallos buenos. "La utilidad estriba, precisamente, en separar lo utilizable de lo que debe ser rechazado", proseguía el presidente, ya que ese momento histórico en el que se iniciaba un tiempo nuevo era la "hora de diagnósticos".

Esta última expresión metafórica de naturaleza médica le servía a Domínguez para continuar con la cirugía y el bisturí: si en el asunto fallero había que operar, así se haría, porque a España se le servía de muchas maneras, "y no es menos laudable ni peligrosa esta de servirse de la pluma y la palabra como de un limpio bisturí, previamente aséptico de pasiones mezquinas y cursilerías baratas, quemado en la llama viva de una pasión hispánica ardiente y combativa». Había partes, por tanto, susceptibles de ser extirpadas, y estas no eran otras que aquellas que, en los años previos, habían pervertido la fiesta, conformando ese modo de ser fallero "recargado de localismo pintoresco e irresponsable (...), desbordamiento de todo ese barato mundillo chalero, falsamente folklórico, aplebeyado y grueso» ${ }^{8}$; el mismo que, de forma radical a lo largo del periodo republicano, había arrinconado al verdadero ingenio valenciano -un ingenio que, si bien era cierto, no era un ingenio fino, sí era al menos chispeante y, en ningún caso, tentado por las «descomunales frutas prohibidas». Llegado el nuevo Estado, las Fallas debían liberarse de esos elementos perniciosos para convertirse en una celebración a tono con los nuevos aires de Victoria.

El discurso de Domínguez era, como se ve, contundente, pero no por ello resultaba original ni novedoso. Más bien al contrario, era un discurso que se insertaba plenamente dentro de una retórica de posguerra centrada en denunciar lo que se consideraba la perversión del verdadero ser de España acontecido durante el periodo republicano, una perversión producida a través de la distorsión que sucedía cuando lo popular se trocaba en populachero, cuando el patriotismo se tornaba en patrioterismo o cuando el españolismo se convertía en españolería. Así lo había dejado claro a menos de dos

6. La Junta Central Fallera, dependiente del Ayuntamiento, se creó a finales de noviembre de 1939. Su creación se puede leer en Las Provincias, 26 de noviembre de 1939.

7. Hernández, Gil-Manuel: Falles i franquisme a València. Catarroja: Afers, 1996.

8. Para el significado del adjetivo chalero, ver la nota 83.

9. Domínguez, Martín: Rumbos de Orden Nuevo. Las Fallas. Valencia: Tipografía artística, 1940. 
meses de la victoria el mismo ministro de la Gobernación, Ramón Serrano Suñer, en un discurso ampliamente divulgado que parecía inspirar, por su similitud, las palabras del presidente de la Comisión de Festejos valenciano ${ }^{10}$. Y así se difundía de forma transversal a través de discursos, arengas, editoriales y proclamas — con mucha contundencia por la parte de Falange, aunque no solo- centradas en señalar con dedo acusatorio dónde estaba el peligro de la desviación y cuáles eran, a cambio, los valores y atributos de la verdadera España. De este modo, instando a alejarse plenamente de la versión bufa, chabacana e histriónica que había dominado durante el periodo republicano, se clamaba por que la nación se mostrase vigorosa, fuerte y decidida, a la par que sobria, rigurosa, recta o seria como forma de conjurar los excesos que amenazaban con deformarla ${ }^{11}$.

Bastaba, a este respecto, leer la prensa durante los días de la celebración de las Fallas de 1940 para encontrarse con elocuentes textos que insistían en lo expuesto. Así ocurría, por ejemplo, con el texto de Eugenio Montes, publicado en el diario falangista Levante en plenas jornadas falleras. En él, el conocido escritor aludía a que lo que más temía era a todo lo que «inunda con falso pintoresquismo de una mentirosa españolería" el país, esa "picaresca greñuda, ineducada, piojosa" propia del Frente Popular que había tomado «lo popular por proletario y plebeyo, y por nacional lo inferior». La diferencia no podía ser más clara: para el régimen anterior, España era «lo de abajo»; para el nuevo Estado, España era — no en vano, el artículo se titulaba "La cueva y el aire»— "lo de arriba»" ${ }^{2}$.

La asunción de la que parte este artículo es la de que los valores mencionados - aquellos que oponían una nación fuerte, lineal y austera a esa otra vulgar y folclorista- pueden ser interpretados en clave de género ${ }^{13}$. En concreto, se parte de la idea de que los primeros pueden ser condensados en la noción de virilidad, considerada intrínseca a la nueva España franquista y con capacidad de funcionar como un arquetipo transgenérico con el que definir tanto a la propia nación como a los hombres y mujeres que la representaban. A cambio, teniendo en cuenta que el género se manifiesta siempre de una manera relacional, los segundos valores aludidos pueden interpretarse como la representación de una antiEspaña — aquella que había alcanzado su paroxismo en la República-considerada afeminada ${ }^{14}$. La idea no es sorprendente:

10. El ministro se había referido a acabar con la «españolería trágica», en este caso, del Madrid decadente y castizo. Las declaraciones de Serrano Suñer están en Arriba, 22 de mayo de 1939.

11. Un buen ejemplo lo constituye el editorial "De la vanagloria a la austeridad", Arriba España, 27 de septiembre de 1939 .

12. MonTEs, Eugenio: "La cueva y el aire», Levante, 17 de marzo de 1940.

13. Existe una abundante bibliografía sobre el vínculo entre género y nación. Los principales trabajos están analizados en el estado de la cuestión de ANDREu, Xavier: "El género de las naciones. Un balance y cuatro propuestas", Ayer, 106, 2017, pp. 21-46.

14. Siguiendo a Joan Scott en su reflexión sobre la oposición masculino/femenino, considero que también la virilidad y el afeminamiento pueden comprenderse como «un conjunto de referencias simbóli- 
mostrando claras continuidades con las décadas previas, el discurso sobre la nación del primer franquismo planteó una idea de virilidad conformada en base a atributos que hablaban de ímpetu, decisión, arrojo o fuerza propios de una nación militarizada y victoriosa que se complementaban con la sobriedad, el autocontrol, la austeridad y la compostura de una España que, gracias al orden, se alejaba del desbordamiento y de la demasía propias de la barbarie ${ }^{15}$. Lo interesante de la oposición planteada — virilidad/afeminamiento - es que se establece a partir de la consideración normativa de lo viril como representativo de la nación y de lo afeminado como su distorsión, una distorsión - y este es otro de los puntos asumidos en el presente artículo por partir de un trabajo previo- que podía producirse tanto por el camino del defecto como por el del exceso: por defecto por cuanto que había afeminamiento en la versión de la nación cómoda, frívola, blanda, chata o fofa que pervertía - por no llegar- el vigor y el impulso de esta; por exceso porque la deformación también se producía a base de rebasar la compostura y desembocar en la caricatura patriotera — ya lo había advertido el propio José Antonio Primo de Rivera- de una versión chabacana, mixtificada y grotesca de la patria ${ }^{16}$.

Fue precisamente este exceso el que preocupó en no pocas manifestaciones festivas, populares o artísticas durante la inmediata posguerra, incluidas las Fallas. El problema y la inquietud residían en que la frontera que separaba el colorín del color, como apuntaba el mismo Martín Domínguez, no siempre era nítida ni difícil de traspasar. Era por ello que, si la Victoria suponía «una revisión y valorización de todos los elementos nacionales», un orden nuevo que todo lo integraba e informaba, en esta revisión debían incluirse no solo «los altos conceptos que inspiran la política, la economía y la espiritualidad", sino, también, «los perfiles —al parecer baladíes - de unas fiestas en que el pueblo se manifiesta y solaza». El objetivo era, por tanto, que, sometiéndose a las directrices políticas del nuevo Estado, las Fallas no desentonasen — por folcloristas y vulgares- ni con Valencia, ni con España, representando dignamente unos verdaderos valores patrios que se pensaban intrínsecamente viriles.

cas» que definen "cualidades abstractas y características (...) En estos usos, no hay nada que impida a los individuos de ningún sexo aceptar tales definiciones». Ver ScotT, Joan: «Sobre lenguaje, género e historia de la clase obrera». En: Sсотт, Joan: Género e Historia. México: F.C.E., 2008, p. 89.

15. La vinculación del orden con la virilidad, en ARESTI, Nerea: «El gentleman y el bárbaro. Masculinidad y civilización en el nacionalismo vasco (1893-1937)", Cuadernos de Historia Contemporánea, 39, 2017, pp. 83-103. De la misma autora, "Masculinidad y nación en la España de los años 1920 y 1930." Mélanges de la Casa de Velázquez, 42(2), 2012, pp. 55-72. Para las décadas previas, ver también Torres, Gemma: La virilitat d'Espanya a l'Àfrica, València: Institució Alfons el Magnànim-Afers, 2020.

16. Para ver el desarrollo de todo el argumento que aquí se toma como punto de partida, Box, Zira: "Los atributos de la nación. Género y clase en la España franquista». En: Lemus, Encarnación y PeÑA, Manuel (eds).: Alianzas y propaganda durante el primer franquismo. Barcelona: Ariel, 2019, pp. 125-146 
El objetivo de este artículo es analizar el discurso desplegado en torno a las Fallas de la Victoria (aquellas celebradas en marzo de 1940) a través de la hipótesis de su virilización. Desde este punto de vista, la idea que se pretende argumentar en las páginas que siguen es que la inserción dentro de la retórica viril de posguerra de una festividad eminentemente popular, satírica y verbenera como la que nos ocupa y, por tanto, próxima al peligro del afeminamiento, necesitó de ciertas resignificaciones, explicaciones y afinamientos. Así, la intención de este texto es analizar los elementos utilizados para llevarlos a cabo y calibrar, en la parte final del artículo, el éxito logrado al respecto. Como advertencia de partida cabe señalar que el mencionado discurso de la virilidad fue, como se señaló en líneas precedentes, transversal, es decir, fue asumido por las diferentes culturas políticas que conformaron la dictadura con las variaciones propias de cada una de ellas. De este modo, si indudablemente se trató de una retórica plenamente compatible con la ideología fascista de Falange, igualmente lo fue con los sectores católicos y reaccionarios que, durante los años de posguerra, defendieron un proyecto de recristianización que también ha sido calificado recientemente por Mónica Moreno como de viril ${ }^{17}$. En este sentido, en el caso de Valencia, tal y como se verá, la dignificación de las Fallas destinada a que pudiesen representar a la nación en 1940 fue desarrollada por diversas publicaciones e instituciones políticas - comenzando por al propio ayuntamiento, ocupado por destacados carlistas - que representaron a los diferentes sectores del régimen ${ }^{18}$.

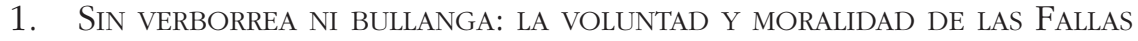

El 25 de junio de 1939, el diario falangista Levante publicaba un breve artículo destinado a ensalzar la vuelta a la alegre normalidad que vivía Valencia tras la victoria. Si apenas hacía pocos meses que la ciudad aún seguía tomada por «aquel espíritu feo, chabacano" del periodo republicano anterior, cabía congratularse de que hubiese vuelto el carácter popular y alegre de los valencianos tras la entrada de las tropas franquistas en ella ${ }^{19}$. El texto aludía a las meriendas, los bailes populares, las paellas y las verbenas que se habían comenzado a celebrar de forma espontánea como ejemplo de la alegría natural de la ciudad del Turia. Incluso, apuntaba el artículo, comenzaban a verse ya las verbenas que las distintas comisiones falleras destinaban a la recaudación de fondos

17. Moreno Seco, Mónica: «Masculinidades y religión. Los Hombres de Acción Católica en el franquismo». En: Blasco Herranz, Inmaculada (ed.): Mujeres, hombres y catolicismo en la España contemporánea. Nuevas visiones desde la Historia, València: Tirant Lo Blanch, 2018, pp. 142-143.

18. Para la contextualización de la València de posguerra y las pugnas políticas ver GiNés, Andreu: La instauració del franquisme al País Valencià, València: PUV, 2010.

19. Los entrecomillados pertenecen al artículo "El milagro de las tres Primaveras", Levante, 23 de marzo de 1940. 
para las celebraciones de San José: unas cuantas sillas formando un corro, un puesto de horchata, varios farolillos colgados por allí, algunos aficionados a la música y la verbena ya estaba organizada hasta las primeras horas de la madrugada. Así era el carácter valenciano, se insistía, y a lo que se veía, "ya no tenemos remedio». Sin embargo, advertía el articulista, era necesario agregar unas últimas palabras para recordar que «las preocupaciones por las fiestecitas» no debían hacer olvidar "aquel deber que tenemos contraído, después de ganar la guerra hemos de conseguir la Victoria de la Paz, para la que también se necesita de un supremo esfuerzo» ${ }^{20}$.

La advertencia del diario valenciano era clara y se iba a dejar sentir en el discurso oficial de las Fallas de la Victoria, porque si el nuevo Estado se narraba como inherentemente viril, había que destacar los aspectos más serios de la fiesta y reorientar, a cambio, sus elementos más alegres, superficiales y coloridos a través de las resignificaciones y recontextualizaciones que evitasen cualquier tipo de equívoco. En realidad, una primera inserción de las fiestas dentro del discurso victorioso resultaba fácil gracias a su propia fecha de celebración: la llegada de la primavera y las posibilidades que ofrecía para jugar con la metáfora palingenésica, dominante en la retórica de posguerra. En 1940, esta palingenesia — literal y metafórica- ocurría, además, por triplicado: no solo se celebraba el primer aniversario del final de la guerra y, con él, la resurrección de la patria (la primavera de la Victoria, como señalaba Levante), sino que llegaba, literalmente, la nueva estación que ponía fin al invierno y permitía el nuevo resurgir de la vida (la primavera de la Naturaleza) al tiempo que se producía la coincidencia de las fiestas falleras con la Semana Santa (la primavera de la Gracia) ${ }^{21}$.

Si por fecha no parecía difícil, por tanto, vincular a las Fallas con las emociones triunfantes, a ello contribuía, también, uno de los elementos falleros por excelencia: el fuego, símbolo de la purificación y de la renovación cuyas connotaciones hablaban no solo de destrucción sino, simultáneamente, de esperanza ${ }^{22}$. Había en este fuego un significado metafórico que, con una intención moralizante, servía para alejar al individuo de los componentes más frívolos de la fiesta e incidir, a cambio, en el hecho de que las Fallas ofrecían la oportunidad de recogimiento y mejora personal. De hecho, la cremà (la quema), el gran final de la fiesta, era el momento en el que todo ardía y en el que se podía combatir el vicio echando a la pira lo feo, lo malo y los defectos propios para que se convirtieran en cenizas $^{23}$. Pero la cremà también era el instante en el que las llamas ofrecían al conjunto del país una lección que —según se advertía

20. "Incluso vuelven las verbenas falleras», Levante, 25 de junio de 1939.

21. "El milagro de las tres Primaveras", Levante, 23 de marzo de 1940. Las alusiones a la primavera fueron constantes. Por ejemplo, Coello, Vicente: "Marzo, en la puerta de nuestra primavera», Fallas 1940, marzo de 1940.

22. AdAlid, Rafael: "Foc i flames", Pensat $i$ Fet, marzo de 1940.

23. Desamparants Sarthous, Regina: "L'IV dels Jocs Florals», Pensat i Fet, marzo de 1940. 
desde Levante - no se podía desaprovechar: en el fuego "renovador y primaveral» debían arder los «trastos viejos, cosas caducas, rutinas de viejas y arrumbadas políticas» con las que habría de desaparecer la "vencida invernada de la decadencia española» ${ }^{24}$.

Había, como se ve, elementos que facilitaban la vinculación fallera al discurso victorioso. Sin embargo, no bastaba simplemente con emparentarlo con él: había también que depurarlo para que resultase una celebración propia de una nación viril. Ciertamente, la insistencia en que la fiesta debía dignificarse no era difícil de encontrar, tanto dentro del discurso oficial fallero como en la prensa - ya fuera falangista o de carácter más conservador - de posguerra. Así lo señalaba, por ejemplo, Libro Fallero, el órgano oficial de la Junta Central Fallera, en su primer número, publicado en marzo de $1940^{25}$. Lo hacía a través de un artículo inaugural escrito por el periodista y escritor monárquico José Gutiérrez-Ravé, quien, dejando claro que las Fallas habían de tener "una modalidad nueva» que constituyese «una nueva página enorgullecedora para la Valencia victoriosa de 1940", apuntaba que, una vez prohibidos los temas míseros y la politiquería, el tantas veces comprobado ingenio valenciano debía derivar hacia motivos más altos y espirituales: debía «dignificar» y «depurar» — nótese que los verbos eran inequívocos- «esta fiesta única netamente valenciana», apartándola, «esperamos que definitivamente, de cierta propensión hacia la chabacanería y plebeyez que en parte tuvo, especialmente en los funestos años posteriores a $1931 »^{26}$.

Para ello, se consideraba que debían, incluso, transformarse y dignificarse los llibrets - los folletos destinados a explicar el contenido de cada Falla-, tal y como reivindicaba otro artículo publicado en el órgano oficial de la Junta Central Fallera, por ser estos, en origen, textos dedicados a la parte más baja de la población, "a la que con cuatro chirigotas y unos cuantos chismes de vecindario amasado con cuantas sales pornográficas tenía el autor a mano» le bastaba. Si, bien desde principios de siglo, la destacada asociación Lo Rat Penat había realizado un notable esfuerzo por realzarlos y convertirlos en publicaciones decentes, reconocía el mencionado artículo, tras los años de la guerra era importante que los autores cuidasen los textos 27 . Para ello, se debía proscribir totalmente el protagonismo de los anuncios - esos patrocinados "por el dueño de un bar o de una botigueta de salses»— - y esmerarse en la redacción para poder mostrar con orgullo «la colección de tan simpáticos folletos como el más acabado modelo de literatura valenciana popular, chispeante, fina y, sobre todo, decente ${ }^{28}$.

24. "Las Fallas de la Victoria», Levante, 17 de marzo de 1940.

25. La publicación de la Junta Central Fallera está analizada en BALLESTER, Josep: «Entre la desvirtuació, l'argúcia i la represa: la literatura i la festa fallera a la posguerra", Revista d'Estudis Fallers, 3, 1996 , pp. 66-67.

26. GutiérREz-Ravé, José: "Valencia victoriosa», Libro Fallero, 14-19 de marzo de 1940.

27. Lo Rat Penat es una asociación creada en 1878 que ha representado el regionalismo conservador valenciano. Ha estado vinculada a la festividad fallera, creando en 1895 los premios a las mejores Fallas.

28. Guastavino Robba, Severino: "La dignificación del 'Llibret' de Falla», Libro Fallero, 14-19 de marzo de 1940. 
Se sumaba a las peticiones de depuración de la fiesta la revista Pensat $i$ Fet, la publicación fallera más importante del momento y reeditada de nuevo tras la guerra con un marcado carácter católico, en su primer número editado en dictadura ${ }^{29}$. Según se podía leer en la declaración de intenciones con la que se abría la reedición, la revista se presentaba con una misión: impedir que la bajeza, lo plebeyo y lo falsamente artístico ocupasen el lugar de lo sincero y lo legítimo. La alta defensa del espíritu de España, se aclaraba, así lo marcaba ${ }^{30}$.

Precisamente, la propia justificación del título de la revista, Pensat i Fet — "pensado y hecho» en castellano- - alusivo al conocido dicho supuestamente representativo del carácter valenciano basado en la espontaneidad y en la acción inmediata, era una muestra de las resignificaciones que protagonizaba el discurso sobre las Fallas. Especialmente crítico con el dicho se había mostrado Martín Domínguez en su discurso radiado de diciembre de 1939. "No y no", había bramado el presidente de la Comisión de Festejos, no había nada en el mundo que tuviese algún valor que hubiese sido "pensat i fet", porque todo lo que lo tenía había sido hecho después de mucho pensamiento y elaboración. "Aquí solemos creer lo contrario", se lamentaba, "Somos la tierra de la alegre facilidad", confundiendo el esplendor de los frutos y flores de la tierra con la falta de esfuerzo, a pesar de que el labrador y el jardinero bien sabían que la mitad de la obra era un don del Cielo, pero la otra mitad, obra de su celo y su labor. "Yo haría grabar en todas las esquinas de Valencia "Facilidad, mala novia"”, continuaba Domínguez, para que quedase claro que lo que se necesitaba era perseverancia, rigor y disciplina ${ }^{31}$.

Efectivamente, la facilidad era uno de los enemigos a extirpar, porque la cercanía con la superficialidad y frivolidad de quien no era consciente de la dificultad de la victoria recordaban a esa versión afeminada que no había sabido estar a la altura de los tiempos ${ }^{32}$. En realidad, explicaba un artículo significativamente nominado «Justificació del pensat i fet», en ningún caso debía entenderse el título como impremeditación, «tópico estúpido para designar toda obra falta de reflexión, toda ausencia de previsión, toda improvisación desatinada ${ }^{33}$, sino como una llamada al desagrado que sentía el

29. Fundada en 1912, su publicación solo se interrumpió durante los años de la guerra, retomándose con un número anual a partir de 1940. Como apunta Josep Ballester, fue la revista fallera de más calidad, la primera escrita en valenciano de acuerdo con las Normes de Castelló y, junto a su carácter católico, fue también una plataforma para el valencianismo cultural de posguerra. BALLESTER, Josep: «Entre la desvirtuació, l'argúcia i la represa», pp. 67-68.

30. Chávarri, L.: "Camí, Pensat i Fet, marzo de 1940.

31. Domínguez, Martín: Rumbos de Orden Nuevo.

32. La similitud de este tipo de discurso con el discurso regeneracionista previo, en VázQuez, Francisco y Cleminson, Richard: "En busca de hombres". Regeneracionismo y crisis de masculinidad (España 18981959)». En: Los invisibles. Una bistoria de la homosexualidad masculina en España, 1850-1939. Granada: Comares, 2011, pp. 171-230.

33. Adlert Noguerol, Miquel: «ustificació del Pensat y Fet», Pensat i Fet, marzo de 1940. 
pueblo valenciano por el burocratismo entorpecedor, por el formulismo inútil y por el espíritu que eternizaba las soluciones. Por eso, "pensat i fet" era el paso inmediato del pensamiento a la realidad sin pasar por el cenagal de las palabras vacías y de la verborrea, tan alejadas de la virilidad ${ }^{34}$; era - y aquí se desplegaba una explícita virilización del dicho que resumía al conjunto del pueblo valenciano- «afirmación rotunda de decisión, amor a la línea recta, predilección por las soluciones verticales, odio a las hipócritas sinuosidades, desdén de la pereza destructora. En resumen, condensa la actividad, la acción y el dinamismo» ${ }^{35}$.

Que en pocos sitios estuviese peor empleada la deformación y el retorcimiento del "pensat i fet» que en las Fallas demostraba lo anterior. De hecho, la fiesta era la antítesis de cualquier forma de facilidad, continuaba el mencionado texto. Porque esta, lejos de ser una mera explosión de jolgorio, representaba, a través de la laboriosidad necesitada para la construcción de las artísticas Fallas, de la dedicación, trabajo y esfuerzo del que tan bien era capaz el pueblo de Valencia. Existía, de hecho, una identificación entre la psicología que dejaban entrever las Fallas y los propios valencianos: una psicología que remitía a un carácter trabajador, constante, paciente y con capacidad de aguantar los reveses y los sinsabores ${ }^{36}$.

Este era, precisamente, un primer elemento discursivo ampliamente utilizado en el discurso de posguerra sobre la celebración que nos ocupa: la insistencia en que las Fallas no solo eran exhibición festiva, sino, también, muestra de la tenacidad, la voluntad, el trabajo y la capacidad de esfuerzo de sus gentes. Así lo hacía el secretario general de la Asociación de Prensa de Madrid, Francisco Casares, uno de los invitados oficiales a la primera celebración fallera, cuando señalaba que marzo de 1940 ejemplificaba el triunfo de la tradición a base de vigor y voluntad — ambas, cualidades viriles-, y a base de sentido vocacional y de rescate de una fiesta que al pueblo valenciano le era tan propia ${ }^{37}$. Es más, escribía el mismo Martín Domínguez como pluma invitada en Libro Fallero, sería bueno que las Fallas se organizasen en el futuro a través de los Sindicatos, señalando, de este modo, la importancia del componente del trabajo dentro de la fiesta. El resultado sería, no solo mayores ventajas económicas y organizativas que la situarían más próxima de los valores de la nueva España, sino, al mismo tiempo - y más significativo para el argumento que nos ocupa-, conllevaría "resultados muy fertilizantes» en lo que al humor satírico inherente a la celebración respectaba. Porque no se podía olvidar: había una gracia «aburguesada y estática, chismosilla y vulgar, propia de la gente desocupada»; y había otra gracia, «más musculada y saludable» — se

34. Al igual que en la nota 29, las continuidades con el regeneracionismo en VÁzQuez, Francisco y Cleminson, Richard: "En busca de hombres».

35. "Justificació del pensat i fet", Pensat $i$ Fet, marzo de 1940.

36. Adlert Noguerol, Miquel: "Lloa i diatriba de la Falla", Pensat i Fet, marzo de 1940.

37. Casares, Francisco: "La tradición liberada", Las Provincias, 20 de marzo de 1940. 
recurría, como se ve, a adjetivos a tono con la virilidad nacional imperante-, propia de "la gente que trabaja y brega", resultando, este último, un ingenio "menos mordaz que el simple comadreo, pero más agudo, fino y dinámico». Y es que, cuando la alegría se vinculaba con el trabajo, concluía el regidor, podían esperarse los mejores frutos de $\tan$ fecunda alianza ${ }^{38}$.

Se desterraba del discurso sobre las Fallas, en consecuencia, la facilidad para incidir en el trabajo y el esfuerzo y, junto a ella, también lo hacían la jactancia y la autocomplacencia, cualidades opuestas a la virilidad española que recordaban a la versión chabacana y castiza de la antiEspaña liberal y afeminada ${ }^{39}$. Lo especificaba con claridad Miquel Adlert, miembro de la junta directiva de Lo Rat Penat: si el arte fallero era y debía ser loado, también habían de señalarse sus diatribas para que no se cayese en simple adulación. Se hacía necesario subrayar que el verdadero arte de las Fallas no era pretencioso ni procaz, resultando inadecuado lo que el escritor denominaba la "Falla homenaje», que era cuando se glorificaba cualquier cosa y cuando el resultado, por petulante, resultaba "opuesto al verdadero tema de las Fallas» ${ }^{40}$.

Si la tenacidad, el esfuerzo, el vigor o la voluntad resultaban fáciles de subrayar a través del señalamiento de las figuras artísticas tan laboriosamente trabajadas que conformaban las distintas Fallas, un segundo aspecto en el que se centró el discurso de posguerra fue en la virilización de la algarabía propia de la fiesta. La festividad, no cabía duda, era una celebración de alegría, diversión y ruido, pero, también —advertía Josep Payá Espinós_- de sentimiento, una fiesta en la que, junto al bullicio, se dejaban ver los valores que formaban el espíritu valenciano: bienestar, belleza y moralidad ${ }^{41}$. Era justo este último rasgo, plenamente opuesto a cualquier forma de desvío y abandono de la rectitud propia de una nación viril, el que quedaba especialmente recalcado a través del carácter religioso que tenía la fiesta, una religiosidad que, a lo largo de la dictadura, adquiriría progresivo protagonismo y que concedía incidir en el recogimiento y las virtudes de una festividad que, en décadas previas y a lo largo de su propia historia, había mostrado no pocos elementos transgresores ${ }^{42}$. Específicamente, la coincidencia de las Fallas de la Victoria con el ciclo ritual de la Semana Santa impelía, además, a resaltar que, al lado de la alegría denominada «legítima», no podía olvidarse el dolor

38. Domínguez, Martín: "Versión moderna y proyección al futuro de las Fallas», Libro Fallero, 14-19 de marzo de 1940 .

39. Así lo resumiría Pedro Laín Entralgo cuando hablase de la «tesis oficial del patriotismo grueso y verbenero" del «Somos unos tíos estupendos» propia de la "campechanería de darse palmaditas en la espalda" tan poco seria y tan propia de la época liberal. Ver «España y la técnica». Escorial, 5, 1941.

40. Adlert Noguerol, Miquel: "Lloa i diatriba de la Falla", Pensat $i$ Fet, marzo de 1940.

41. Paý́ Espinós, Josep: "Festa de les Falles», Pensat i Fet, marzo de 1940.

42. Aparte de la ya mencionada monografía de Gil-Manuel Hernàndez (Falles i franquisme), del mismo autor se puede ver «El triomf de la tradició flexible. La celebració de la identitat fallera a través de l'Ofrena de flors a la Mare de Déu dels Desemparats de València», Revista d'Estudis Fallers, 12, 2007, pp. 42-60. 
pasado, el cual dotaba a la vida de "ponderación y sentido", cualidades propias de la nación viril ${ }^{43}$.

Las Fallas constituían una celebración moral y, para que no hubiese ninguna duda, había que diferenciar la sana alegría de la «muchedumbre no torva y cruel» de 1940 de las «riadas bullangueras» que, en los años previos a la guerra, habían convertido una fiesta que habría podido tener un cierto encanto simpático y pintoresco en algo «chabacano e impertinente». Acontecida la victoria, la «invasión» de esas hordas se sustituía por la muchedumbre jubilosa y alegre que, a la hora de celebrar la festividad y sin olvidar el momento que se vivía, saldría a la calle con «la palma abierta, brazo en alto y con estrofas de victoria en los labios ${ }^{44}$. Es más: observar las Fallas en los pueblos de la huerta de Valencia permitía ver que la fiesta era fraterna y de unción popular, en la que se ponía de manifiesto el "alto coeficiente de civismo en la respetuosa tolerancia mutua» ${ }^{45}$.

Algunas medidas explícitas se destinaron, justamente, a controlar el ruido y el posible desbocamiento de la alegría festiva. Así ocurría con la prohibición — so pena de multas o arrestos - de vender o tirar cohetes y petardos que no figurasen en las tracas y fuegos artificiales de los programas oficiales, dictada por el gobernador civil, Francisco Planas de Tovar, y reiterada por la Junta Central Fallera ante las diversas comisiones de Fallas. Y así ocurría, también, con las instrucciones que se daban a las Organizaciones Juveniles invitadas, quienes tenían terminantemente prohibido circular por la ciudad después de las diez de la noche y a quienes se advertía que cualquier acto que se olvidase de las "nomas y estilo» que debían imperar sería sancionado con severidad. La normativa horaria solo se ampliaba el día de San José: con tal de poder asistir a la cremà fallera, la hora de recogida se retrasaba, esa noche, hasta la una de la madrugada ${ }^{46}$.

Especialmente significativas eran las medidas que implicaban a las Organizaciones invitadas para la ocasión porque, si las Fallas tenían una inequívoca vocación turística desde la década de los años $20^{47}$, parte de los esfuerzos por virilizarlas iban a encaminarse a que tanto la imagen de Valencia que se proyectaba en el resto del país, como la de su festividad, se ajustasen a los valores y atributos que definían a la España de posguerra. En esa misma noche de San José del 19 de marzo de 1940, mientras ardía

43. "Meditación en la Semana Santa de España», Levante, 20 de marzo de 1940.

44. Las alusiones a las riadas bullangueras y a la invasión, en Domínguez, Martín: Rumbos de Orden Nuevo. Las de "muchedumbre no torva" y el saludo brazo en alto, en Mira, Nicasio: "Alborada fallera", Libro Fallero, 14-19 de marzo de 1940.

45. Morante, Jesús: "Las Fallas en los pueblos valencianos», Libro Fallero, 14-19 de marzo de 1940.

46. Toda la información, en "Los festejos falleros», Las Provincias, 17 de marzo de 1940.

47. La potenciación turística de las Fallas fue orquestada por la Sociedad Valenciana del Fomento del Turismo, la cual, desde 1927, organizó los trenes falleros desde Madrid a Valencia. Ver ARIÑo, Antonio: La ciudad ritual, p. 156. Un resumen del trabajo realizado por la Sociedad explicado por su presidente, el Barón de Casa-Soler, en "Las Fallas de San José y el turismo», Libro Fallero, 14-19 de marzo de 1940. 
la Falla del céntrico Mercado Central, Víctor Ruiz Albéniz, más conocido como El Tebib Arrumi, acompañado del director general de Prensa y Propaganda, José Antonio Jiménez Arnau, y de un conjunto de periodistas y escritores convidados a las oficinas de Radio Valencia para asistir a la cremà, señalaban la necesidad de que, "con fe y disciplina", se ganase la paz. Era una alusión muy similar a que realizaba el locutor de Radio Nacional, Fernando Fernández de Córdoba, cuando, ante el espectáculo de las llamas convirtiendo en cenizas una de las Fallas más populares de la ciudad, aconsejaba a todos los españoles — también él— «unión y disciplina». Así se escuchaba por boca de algunos de los más destacados invitados de honor a través de los micrófonos de Radio Valencia ${ }^{48}$. Y así iba a continuar como parte del complejo y ambivalente intento de virilizar y disciplinar la imagen de la fiesta y de su ciudad, una ciudad mediterránea, soleada, alegre y florida que tradicionalmente había sido representada — ahí estaba el reto- con cualidades femeninas.

\section{LA FEMINIDAD VIRIL DE LA MEDITERRÁNEA VALENCIA}

"¿No habéis visto nunca la cara de una mujer bonita cuando pugna en esfuerzos, a veces inútiles, por apagar la risa que, estallante, quiere dibujarse en las líneas de su rostro?», preguntaba Nicasio Mira desde las páginas de Libro Fallero. Lo hacía a propósito de la despertà, el clarín anunciador de las celebraciones de cada día que, justo el despuntar el amanecer, señalaba el comienzo de las celebraciones. El interrogante retórico le servía, simultáneamente, para establecer un símil con la ciudad: así era también Valencia en el inquieto preceder de la fiesta, una «mujer bonita que quiere contener el deseo de su estallante alegría para la fecha señalada", pero a quien "el brillo luminoso de los ojos» delataba ${ }^{49}$.

La identificación de Valencia con lo femenino, a veces de forma tan explícita como en su equiparación con una mujer, no era nueva. Desde la segunda mitad del siglo XIX, dentro del discurso regionalista de la Restauración, la feminización de esas patrias chicas que se contraponían a una Castilla masculina se había ido plasmando en las artes y en la literatura, sirviendo, al mismo tiempo, para afianzar la subordinación de las regiones al proyecto nacional ${ }^{50}$. Los elementos que, en este caso, definían a la región como intrínsecamente femenina eran claros: las flores, la huerta, el regadío o el mar conformaban esa imagen del suave Levante que se oponía a la sequedad y adustez castellanas.

48. "Valencia al día", Las Provincias, 20 de marzo de 1940.

49. Mira, Nicasio: "Alborada Fallera", Libro Fallero, 14-19 de marzo de 1940.

50. Así lo sugiere ARChilés, Ferran: «Piel moruna, piel imperial. Imperialismo, nación y género en la España de la Restauración (1880-1909)", Mélanges de la Casa de Velázquez, 42 (2), 2012, p. 46. 
También el discurso desarrollado en torno a las Fallas, especialmente el dirigido a proyectar un retrato turístico sobre la fiesta y la ciudad, retomó los elementos habituales acerca de la idiosincrasia valenciana. En el artículo que se hacía eco de la invitación cursada a dos mil jóvenes falangistas pertenecientes a los Flechas y Cadetes del Frente de Juventudes para asistir a la fiesta, se aludía a agasajar a los invitados con el sol mediterráneo valenciano, con los naranjos de los vergeles y con el sabor dulce de los frutos típicos de la tierra ${ }^{51}$. De laberinto de palmeras, arcos de claveles y dalias, de llama y de luz, hablaba Guadalupe Segarra ${ }^{52}$. De flores, agua, verde limonar y naranjal divino lo hacía Miguel de Benisa en el poema con el que ponía voz al monumento del Miguelete en el imaginario diálogo con la gallega Torre de Hércules, un diálogo en el que el primero ofrecía a la segunda aquello que era distintivo de Valencia ${ }^{53}$. A olor a azahar, barracas y huertas aludía la historia de amor ficticia entre Adolfo, valenciano, y Rosarito, visitante madrileña, que surgía al hacer el primero de guía de la joven turista durante la fiesta de las Fallas ${ }^{54}$. Y a la explícita comparación de Valencia con una gran flor, toda ella temblorosa de amor y de alegría, capaz de atraer a gentes de todas partes, recurría Vicente Ramírez Bordes en su descripción de la plantà, el momento en el que las Fallas se sacaban de los talleres para lucir en las calles de la ciudad55.

Los elementos, no cabía duda, eran los habituales y contenían un marcado carácter femenino. Sin embargo, a tono con la retórica de posguerra, se desplegó también un discurso destinado a que la innegable naturaleza fértil y mediterránea de Valencia no se confundiera con la cómoda indolencia que, en lugar de aludir a su feminidad, pudiese sugerir —en este caso, por defecto, según se apuntó al inicio de estas páginas - su afeminamiento. La diferencia era suficientemente clara: no era lo primero lo que desafiaba la virilidad de la nación, sino, tal y como se señaló anteriormente, la distorsión que convertían la seriedad, el rigor y la templanza de una nación viril en estruendosas vulgaridades o en fáciles complacencias propias de su versión desviada.

Lo había dejado claro Martín Domínguez en el discurso anteriormente citado. Valencia era una ciudad mediterránea y, por tanto, abierta y un poco vocinglera, pero - no había que confundir - también era una ciudad que sabía cuidar las formas y que no andaba en mangas de camisa precisamente a la hora de la visita. A este respecto, había que insistir que ni Valencia, ni sus fiestas, ya se apuntó en el epígrafe previo, respondían a la chabacanería con la que se las había querido desfigurar. Pero tampoco lo hacían con la mera simplicidad de una alegría superficial y cómoda de simples flores, cielos azules o mares templados que amenazaban con afeminarla, en este caso, por

51. Bel BAdíA, Ángel: «También verán las Fallas!», Libro Fallero, 14-19 de marzo de 1940.

52. Segarra, Guadalupe: "Flores de fuego», Libro Fallero, 14-19 de marzo de 1940.

53. DE BEnISA, Miguel: «Envío del Miguelete a la Torre de Hércules», Libro Fallero, 14-19 de marzo de 1940.

54. Agramunt, Armando: "Noche de Fallas», Libro Fallero, 14-19 de marzo de 1940.

55. Ramírez Bordes, Vicente: «La plantà», Libro Fallero, 14-19 de marzo de 1940. 
pasividad e indolencia. Se hacía necesario, consecuentemente, virilizar su feminidad para que esos rasgos que se desprendían de su paisaje y que parecían definirla no entrasen en contradicción —en esta ocasión, por blandos, frívolos y vacuos- con los atributos de la nueva España.

Reivindicar el Mediterráneo como ejemplo de algunos de los valores propios de la nación de posguerra no era especialmente difícil. Se le podía vincular, en primer lugar, con el pasado clásico, compartido, a la sazón, con la Italia fascista y ejemplo de armonía, templanza y serenidad, a la par que fuerza, ímpetu y poderío, que resonaban en esas aguas valencianas en las que latían aún los hexámetros de Virgilio ${ }^{56}$. Era, precisamente, el pasado romano el que se reivindicaba en la V Concentración de FET y de las JONS que se celebraba en Sagunto, la ciudad industrial situada a treinta kilómetros al norte de Valencia, en coincidencia con las fechas falleras. Si, tal y como se escribía en la crónica del acto, el paso recio y animoso de veinte mil falangistas hacía que la historia dormida se levantase para anunciar la buena nueva de la resurrección de España, el discurso que pronunciaba Vicente Escrivá, jefe provincial de propaganda, era claro. En Sagunto se desplegaban los tres caminos imperiales: el sentido de Imperio, tan propio de Falange y ejemplificado en los restos y vestigios romanos; el sentido del Trabajo y del Progreso, señalado por los Altos Hornos de una ciudad industrializada; y el sentido militar de la Vida, representado por las Milicias en la elocuente descripción de Escrivá: «tensos los músculos, exacto el ademán, altivas las frentes, ansiosas de lauros guerreros». Abajo, para que nada faltase, «el mar, el Mare Nostrum, el mar de la civilización y de la cultura, abierto como una tentación para todas las empresas audaces e imposibles ${ }^{57}$.

Y es que, ante la abnegación, la rapidez, la viveza y, sobre todo, la discreción de las gestas imperiales y marineras, ¿quién podía atreverse, entonces, a hablar de la indolencia mediterránea, de la inconstancia y la veleidad?, se preguntaba desde las páginas de Levante el periodista aragonés Martín Abizanda. «Dónde la influencia del sol de Mediodía, que, si para Daudet hacía a los marselleses mentirosos, hace para muchos extranjeros a los españoles perezosos, irascibles y nada consecuentes? ${ }^{58}$. Había, de hecho, que reivindicar el mar de Valencia, pero no ese mar de arrabal y barrio —el mar era algo más que el Cabañal, bramaba un editorial de Levante en alusión al popular barrio marinero-; tampoco ese mar importado metido a trocitos en las piscinas, cuando, sintiéndose febles y disminuidos, los españoles habían abandonado el auténtico genio de España y la elegancia nacional para importar el falso dandismo59. Lo que había que

56. Domínguez, Martín: Rumbos de Orden Nuevo.

57. "Las piedras milenarias de Sagunto afirman su fe en los destinos de España", Levante, 19 de marzo de 1940. La concentración se celebró el 17 de marzo.

58. "Nuestra indolencia mediterránea", Levante, 14 de marzo de 1940.

59. Las ambigüedades de la figura del dandy en su relación con los ideales de masculinidad normativos están señalados, a partir de los trabajos de Joanne Nigel y Gail Bederman, en ARESTI, Nerea: "El gentleman y el bárbaro", p. 97. 
reclamar era la auténtica naturaleza marinera valenciana, la que reflejaba camino y ambición, la que era la puerta florida de Comercio, Historia y Cultura, de conquistas y de imperio ${ }^{60}$.

Desterrando la indolencia y la inacción, el mar se convertía en símbolo de fuerza, civilización y grandeza. También la siempre mentada huerta valenciana, elemento por excelencia de la identidad regional ${ }^{61}$, se podía virilizar apelando, en este caso, a ver más allá de su exuberancia y fertilidad. Lo hacía Jesús Morante y Borrás desde la revista Fallas, en la que relataba el ambiente de las fiestas: mientras la ciudad ardía, la huerta resplandecía, esa huerta que contenía leyendas de ensueño, barracas prestas a levantar el vuelo cual palomas y alquerías bruñidas por el oro del sol; pero una huerta que también eran sus habitantes y su prestancia habitual: los labradores —els llauradors-, nobles y trabajadores que habían sabido faenar duro para convertir en espléndidos jardines lo que no eran en origen sino ásperos terruños ${ }^{62}$.

Valencia era huerta, frutales y regadío y, si el mar la vinculaba con su pasado romano, por este lado de la agricultura y el regadío lo hacía con su pasado árabe. "Sangre mora que en las venas palpita", se podía leer en el poema escrito por Mario Vidal para la revista Libro Fallero ${ }^{63}$. El rasgo era, ciertamente, orientalizante, sin embargo, hacía décadas que se había convertido en un rasgo positivo dentro de un proceso de autoexotización de la propia Valencia. Incluso, figuraba en el himno valenciano, compuesto para la Exposición Regional de 1909 y en el que en sus estrofas aludía al canto del agua que había nacido a ritmos de guitarra mora y a la identificación de la propia Valencia con una sultana a cuyos pies se ofrecían laureles y jardines de rosas, nardos y claveles. A este respecto, como analizaron Ferran Archilés y Marta García Carrión, el pasado moro se veía positivamente, desvinculándolo del factor religioso e identificándolo, a cambio, con la rica tradición agrícola y las artes ${ }^{64}$.

Con todo, en 1940, la asunción de dicho discurso necesitaba, no obstante, de ciertas matizaciones. Lo escribía Pilar Oroz en el número extraordinario que la revista $Y$, órgano principal de la Sección Femenina de Falange, publicaba en marzo de 1940 dedicado a la ciudad del Turia. Refiriéndose a una de las creaciones artísticas de origen

60. "Valencia y el mar", Levante, 27 de junio de 1939.

61. GARCía CARRIÓN, Marta: "La regió en la pantalla. Cinema i identitat regional valenciana en la primera meitat del segle XX", Cercles, 17, 2014, p. 102. Una síntesis, en ArCHILÉs, Ferran: "La identitat valenciana a l'època contemporània: una perspectiva històrica». En: Flor, Vicent (ed.): Nació i identitat. Pensar el País Valencià. Catarroja: Afers, 2013, pp. 21-44.

62. Morante Borrás, Jesús: "Las Fallas, su literatura y ambiente», Fallas 1940, marzo de 1940.

63. Vidal, Mario: "Alegría de fiesta", Libro Fallero, 14-19 de marzo de 1940.

64. ArChilés, Ferran y García CARrión, Marta: «La invención de un himno para una región: Valencia, 1909-1984». En: SeIDEL, Carlos (ed.): Himnos y canciones. Imaginarios colectivos, símbolos e identidades fragmentadas en la España del siglo XX. Granada: Comares, 2016, pp. 141-42. El proceso de autoexotización, en ANDreu, Xavier: El descubrimiento de España. Mito romántico e identidad nacional. Madrid: Taurus, 2016. 
árabe más típicamente valencianas, la cerámica de Manises, señalaba que se trataba de «la más viril y artística de Valencia», realizada bajo el sol levantino y la brisa del Mediterráneo, pero elaborada — que nadie pensase en su facilidad o suavidad- por los duros maniseros que, con callosas manos, amasaban en sus tornos el duro barro ${ }^{65}$. De forma significativa, el mismo número se abría con un reportaje sobre la Sección Femenina de la provincia, realzando las cualidades de su delegada provincial, Aurora de Aynat, por ser firme y vigilante, y por haber sabido desterrar, inflexiblemente, todo cuanto fuera verbalismo y vaciedad ${ }^{66}$. Según se ve, las características de la delegada aludían a su estilo viril compatible con su indudable feminidad y plenamente alejado —eso sí — de la vacuidad y superficialidad del afeminamiento.

En todo caso, no siempre era fácil reclamar la seriedad y virilidad de una ciudad que, no se podía negar, se desbordaba en la alegría de sus fiestas. En parte, la dificultad venía del hecho de que existiesen dos Valencias, tal y como reclamaba la revista El turista fallero, dedicada a explicar al forastero todo el folclore que rodeaba a la festividad, en su primer número de marzo de 1942, dos años después de las inaugurales Fallas de la Victoria. En el texto inicial con el que Valencia daba la bienvenida al amigo turista, se le prevenía de que en esos días de marzo se encontraría con una ciudad alegre y despreocupada, con una Valencia divertida que no cesaba de bailar, cantar, ni de tirar tracas al aire. Una Valencia, en definitiva, "muy mediterránea», que era como decir "con mucha luz, con mucha forma, con mucho color", una Valencia "extrovertida bajo un cielo tibio de azul y un sol azucarado». Sin embargo, se le hacía notar, el turista debía también saber que Valencia tenía otra cara, una que quizá no vería en su visita, pero que era la de una "Valencia trabajadora, infatigable, forjadora de su rica agricultura, de su artesanía incomparable, de su aquilatado arte, de su fino espíritu aristocrático, (y) de su religiosidad acrisolada " ${ }^{67}$. Ahí estaba el escollo: en que la misma ciudad mostrase dos caras tan diferentes y en que por una de ellas se pudiese filtrar la realidad de unas fiestas que, en el fondo, eran verbeneras, ruidosas y localistas y que, por consiguiente y mal que pesase, resultaban, tal y como se verá a continuación, altamente difíciles de virilizar.

\section{UNA REALIDAD MÁS AMBIGUA QUE LA DEL RELATO OFICIAL}

Efectivamente, tal y como señaló acertadamente Gil-Manuel Hernàndez, el discurso oficialista sobre las Fallas tuvo como contrapunto la realidad del mundo fallero, mayoritariamente de origen popular, y sus preferencias temáticas a la hora de realizar las

65. Oroz, Pilar: «Manises», Y. Revista para la mujer, marzo de 1940.

66. "Ser y estar de la Sección Femenina de Valencia", Y. Revista para la mujer, marzo de 1940.

67. "Amigo turista: en nombre de Valencia te damos la bienvenida", El turista fallero, marzo de 1942. 
figuras y de redactar sus correspondientes explicaciones en los llibrets. La censura, claro es, fue explícita, marcando unas líneas férreas entre lo permitido y lo prohibido. Sin embargo, desterrada toda alusión política, social o internacional, y perfilado el carácter satírico para que este se encauzase hacia inocuos motivos cómicos y para que, según se recomendaba desde el Ayuntamiento, se aspirase al humor más que a la ironía, al regocijo sin la ofensa, y a la gracia natural, clara y limpia en lugar de al divertimento fácil, grosero o grueso ${ }^{68}$, quedaba margen para que el resultado de las Fallas fuera diferente a como el discurso oficial lo imaginaba ${ }^{69}$.

Durante los primeros años de dictadura, el repertorio temático fallero más numeroso fue el que Gil-Manuel Hernàndez denominó de manera amplia como «cultural». En él se incluían Fallas dedicadas a la propia fiesta, retratándose en los conjuntos artísticos alusiones a la misma festividad, así como referencias a la música, los símbolos de la tierra, las tradiciones, los monumentos valencianos, la comida típica o, por supuesto, la huerta ${ }^{70}$. Se contribuía, de este modo, a reforzar los elementos clave de la identidad regional valenciana, fuertemente entrelazada con la propia fiesta desde las décadas previas a la guerra civil ${ }^{71}$.

Las consignas establecidas para que los conjuntos artísticos y las figuras se alejasen del mal gusto tan ampliamente denunciado fueron seguidos por algunas Fallas. Tal era el caso, por ejemplo, de la Falla de las Calles Cuenca y Roberto Castrovido, titulada "Lo típico vuelve» y consistente en un sencillo retrato del "resurgir» de las tradicionales y típicas fiestas valencianas, entre las que se incluían tanto festividades religiosas - como el Corpus, San Vicente Mártir o la Semana Santa- como otras de carácter popular — como la Feria de Julio o los diferentes certámenes musicales de las bandas_ ${ }^{72}$.

Se adhería explícitamente al estilo establecido en la posguerra la Falla de Bolsería Tros-Alt, dedicada al comercio y al trabajo valenciano y en cuya explicación recordaba que las fallas de esta hora de resurgimiento no podían «ser cosa liviana de asuntos vulgares e insustanciales», sino que debían inspirarse «en ideas grandes y nobles que abran al espíritu la visión grata de los caminos de redención y engrandecimiento de nuestro pueblo». Por eso, continuaba la mencionada explicación, se habían caricaturizado temas como la cerámica, el arte de la seda, la agricultura de la huerta, el cultivo del

68. Según se explicaba en las bases para la instalación de Fallas en el año 1940, se entendía que la Falla había de ser satírica, pero «satirizando sucesos cómicos, escenas de barrio y críticas de hechos que no tengan carácter político, social o internacional». Caja 63. Archivo Histórico Municipal. Las recomendaciones, en Domínguez, Martín: Rumbos de Orden Nuevo.

69. HeRnÀndez, Gil-Manuel: Falles i franquisme, p. 122. La censura está explicada en las páginas 112-121.

70. Id., pp. 133-139.

71. Tortosa, Rafael: "Les Falles i la política. Entre el valencianisme i el poder (1850-1962)», Sinapsis, 3, 2018, pp. 65-90.

72. Boceto y explicación de la Falla de las Calles Cuenca y Roberto Castrovido, 1940. Caja 79. Archivo Histórico Municipal. 
arroz o las faenas del mar, todas ellas propias del trabajo típico del pueblo valenciano, "pero siempre dentro de las normas del arte y del buen gusto» ${ }^{73}$.

En cualquier caso, no todas las Fallas respetaban las consignas. Había otras en las que la exaltación de la tierra se acercaba peligrosamente al localismo y a la autocomplacencia gruesa y chabacana que tan mal encajaban con el discurso de la virilidad nacional imperante. Tal era el caso, por ejemplo, de la Falla de las calles Cádiz, Patricio Huguet y adyacentes, nominada "Motius valensians» y en la que aparecían representados elementos hilarantes de la valencianidad: según se leía en la explicación del boceto, una traca, una paella, una taberna típica en cuya puerta permanecía un vendedor de cacahuetes "que toda la recaudación se la gasta en vino", una portera dormida sobre la escoba y una cocinera leyendo revistas ${ }^{74}$. En otros casos, la autocomplacencia no era tanto vulgar como grandilocuente e irreflexiva, esa que Pedro Laín Entralgo calificaría como la campechanería tan poco seria de darse palmaditas en la espalda y de considerarse unos tíos estupendos ${ }^{75}$. Así ocurría con una Falla muy próxima a la anterior: la situada en las calles Cádiz y Denia, en el muy fallero barrio de Ruzafa, y cuyo lema era "Lo mejor del mundo Valencia». En ella, lucía el monumento del Miguelete rodeado por el "Mundo entero", el cual se agrupaba "admirando nuestros monumentos y nuestras fiestas» ${ }^{76}$. Como escribía Lucio Ballesteros en Libro Fallero, es que solo en Valencia se hacían las cosas de esa magnífica manera, solo allí el arte tenía una aspiración de ímpetu monumental ${ }^{77}$.

En otras ocasiones, el problema estribaba en que las escenas representadas en la Falla distaban plenamente de esa ponderación inteligente y cuidado exquisito, de ese alarde espléndido de tacto y bondad, de refinamiento moral, de sentido cristiano y de decoro al que había instado el presidente de festejos del consistorio para acercarse, a cambio, a la "actualidad chismográfica de plazuela» tan poco recomendable ${ }^{78}$. Así pasaba con la Falla de las calles Murillo y Encarnación, titulada "Lío vecinal» y consistente en la representación de un grupo de vecinas que, contrariamente al control y la compostura de la virilidad nacional, aparecían pegándose por diversas y pueriles riñas de barrio ${ }^{79}$.

Tampoco el carácter del pueblo valenciano mantenía los rasgos propios de la vencedora España viril en algunas de las descripciones que aparecían en los populares

73. Boceto y explicación de la Falla Bolsería Tros-Alt, 1940. Caja 79. Archivo Histórico Municipal.

74. Boceto y explicación de la Falla de las calles Cádiz, Patricio Huguet y adyacentes. Caja 79. Archivo Histórico Municipal.

75. Ver la nota 36

76. "Lo mejor del mundo Valencia», boceto y explicación de la Falla Cádiz-Denia, 1940. Caja 79. Archivo Histórico Municipal.

77. Lucio Ballesteros, "La noche de la cremà", Libro Fallero, 14-19 de marzo de 1940.

78. Domínguez, Martín: Rumbos de Orden Nuevo.

79. Boceto y explicación de la Falla de las calles Murillo y Encarnación. Caja 79. Archivo Histórico Municipal. 
llibrets de Falla, contrastando abiertamente con el discurso oficial sobre cómo debían depurarse dichos libretos. En ellos, el rigor, el control, la sobriedad o la rectitud que conformaban la nación franquista se desafiaban a base de exceso, gritos, impulso y estruendo. "Que no falte la bullanga i la camorra en el nostre barri», clamaba la publicación fallera del céntrico Mercado Central elocuentemente titulada Crit de festa (Grito de fiesta). En ella, quienes la redactaban se presentaban ante el potencial lector como "los de siempre»: aquellos que en todo momento eran propicios a la juerga, los que huían de la faena y se pasaban la vida en una continua chirigota; aquellos que hacían suyo el refrán de "de la vida sacarás tripa llena y nada más» ${ }^{80}$.

Es cierto que, debido a su reducida tirada, la incidencia de los libretos era mínima, circunscribiéndose, casi exclusivamente, al ámbito de demarcación de los vecinos de barrio $^{81}$. Sin embargo, resulta interesante plantearlo como contraste a las líneas políticas y discursivas del nuevo régimen, corroborando tanto la excepcionalidad del tiempo festivo y las oportunidades que en él se abren para filtrar elementos impensables en otro contexto ${ }^{82}$ como el desafío que ciertas fiestas de carácter popular supusieron a la oficialidad franquista ${ }^{83}$.

Sea como fuere, el carácter valenciano, definido a partir de la propensión a la fiesta y al divertimento —el carácter chalero que había criticado Martín Domínguez_ ${ }^{84}$, fue también aplaudido desde las mismas publicaciones mencionadas previamente, unas publicaciones que pueden ser consideradas oficiales y en las que, simultáneamente, se criticaba lo que en otros artículos se defendía ${ }^{85}$. Así podía leerse en Libro Fallero, el órgano oficial de la Junta Central Fallera, cuando a los auténticos gestores de la fiesta se les definía como "falleros de abolengo y chaleros de estirpe» y como "castizos valencianotes dicharacheros y con un catequismo vecinal a prueba de toda negativa» 86 . Incluso, se defendía y revindicaba el lema "pensat i fet", denostado en el discurso oficial por irreflexivo y poco serio — según se aludió previamente-, como inherente

80. "Presentació", Crit de festa, n 9, marzo de 1940.

81. Ballester, Josep: "Entre la desvirtuació, l’argúcia i la represa», p. 69.

82. Id., p. 65. Así lo analizó, también, ARiÑo, Antonio: La ciudad ritual.

83. Así lo han puesto de manifiesto los trabajos de César Rina en los que se destaca el peso de la comunidad. Por ejemplo, su monografía Los imaginarios franquistas y la religiosidad popular. 1936-1949. Badajoz: Diputación de Badajoz, 2015.

84. El adjetivo chalero como descriptor del carácter valenciano es una castellanización del verbo valenciano xalar, que significa divertirse o disfrutar. Agradezco a Ferran Archilés que me diera a conocer el mencionado verbo.

85. Así ocurría en múltiples publicaciones franquistas. Por ejemplo, para el caso específico del discurso sobre los modelos de feminidad, Ángela Cenarro ha mencionado esta misma simultaneidad, en los mismos número y revistas, de artículos parcialmente contradictorios. Ver CENARRo, Ángela: «La Falange es un modo de ser (mujer): discursos e identidades de género en las publicaciones de la Sección Femenina (1938-1945)", Historia y Política, 37, 2017, pp. 91-120.

86. Hernández-Casajuana, F.: "Los fallos de las Fallas», Libro Fallero, 14-19 de marzo de 1940. 
a la valencianidad: esa era "la norma en que por lo general solemos hacer las cosas en Valencia, hasta las llamadas de gran envergadura", escribía Godofredo Ros, tío del conocido escritor falangista Samuel Ros, desde la misma publicación aseverando todo lo contrario a lo que había explicado Martín Domínguez y a la justificación esgrimida desde Pensat $i$ Fet con respecto al dicho ${ }^{87}$.

También las propias Fallas, como se dijo en páginas previas, se concebían inseparables de la naturaleza de Valencia y de los valencianos ${ }^{88}$. La diferencia se hallaba en que, si bien oficialmente se defendía que este carácter no era otro que el que se desprendía del trabajo, el tesón, la seriedad o la tenacidad — atributos, todos ellos, viriles- ejemplificados en las figuras falleras en las que se faenaba todo el año para que luciesen listas cada mes de marzo, existía, igualmente, otro discurso en el que lo que se destacaban era el ruido y la explosión propios de la fiesta, de su pueblo y de su ciudad.

Y es que, si el valenciano llevaba el fuego en la sangre, parecía lógico que todas sus fiestas se acompañasen de estampidos alegres y de algarabías chillonas ${ }^{89}$. Así eran las Fallas, colocadas entre chistes y donaires, tras algunos descansos y muchas copas, «entre risotadas y gestos alegres de juventud de barrio». En Fallas era imposible, se proseguía desde la publicación Fallero valenciano en 1941, cualquier tipo de reposo en la ciudad: acercándose peligrosamente a la descripción del descontrol y del estruendo propio de lo afeminado, la imagen de la ciudad hablaba de movimiento y convulsión "al compás de músicas enjalbegadas, de estruendosas tracas, de gritos de los vendedores de llibrets, y de gente que bulle, gesticula y grita" al conjuro de este ambiente de pólvora fuerte, una pólvora que hacía hervir la sangre y que quemaba las entrañas «en una lógica locura de primitiva sencillez mediterránea ${ }^{90}$. Como se puede comprobar, pocas descripciones resultaban tan lejanas de la sobriedad, compostura y llamamiento a no descuidar el estilo viril que se había hecho a los invitados a la celebración de 1940 de las Organizaciones Juveniles como la mencionada. Filtrándose entre las costuras del discurso oficial, la realidad de una fiesta de barrio, histriónica y bullanguera evidenciaba que la retórica de la virilidad nacional convivía con aquellas otras que la desafiaban.

87. Ros, Godofredo: «Sobre nuestras fallas», Libro Fallero, 14-19 de marzo de 1940.

88. Así lo señaló Antonio Ariño con el término de "Valencianismo temperamental», apuntando el intercambio entre el carácter valenciano y la fiesta fallera. Ver «La fiesta de las Fallas. Una liturgia civil del valencianismo temperamental", Revista de Antropología social, 1, 1992, pp. 29-60.

89. "Génesis, pasión y muerte de la Falla", Libro Fallero, 14-19 de marzo de 1940.

90. Baixauli, J.: «Rasgos falleros», Fallero valenciano, marzo de 1941. 


\section{Final: NO HaY FALla SIN BUÑUelO}

«El buñuelo es la síntesis de la fiesta. Falla sin buñuelos está incompleta [...] Falla sin buñolería no es Falla», escribía sintéticamente Ricardo Juan en una sentida reivindicación del típico dulce fallero ${ }^{91}$. El reclamo del bollo contrastaba, ciertamente, con la denostación de las rosquillas madrileñas, vinculadas peligrosamente a ese casticismo de organillo y mantón que, desde la exigencia de la virilidad nacional, se denigraba y negaba. En última instancia, el pringoso aceite que se necesitaba para freír ambos dulces tenía el gusto, al igual que los guisotes de cazo proletario, de lo atrozmente plebeyo ${ }^{92}$.

Esta ambivalencia en torno al discurso sobre la tradicional fiesta de las Fallas ha sido el argumento principal de este artículo. Partiendo de que, a lo largo de los primeros años del franquismo, se articuló una concepción sobre la nación a partir de la asunción de su virilidad, en las páginas previas se ha contrastado la retórica oficial desplegada alrededor de las primeras Fallas de posguerra, las celebradas en marzo de 1940, con el discurso y la realidad del mundo fallero. En este sentido, desafiando los distintos atributos de la nación viril, tanto aquellos que hablaban de fuerza, decisión y arrojo como los que aludían a la compostura, el rigor y la sobriedad, las descripciones de una fiesta ruidosa, bullanguera, vecinal y desenfrenada que se deslizaron entre la oficialidad se acercaron a un retrato de la festividad que, por parte de las instituciones políticas y de las plumas intelectuales y periodísticas que copaban la prensa nacional, se criticaba por chabacano, vulgar y afeminado.

En todo caso, y esta es una de las conclusiones que se sostiene aquí, no por específico, el discurso analizado en este texto fue anecdótico. Más bien al contrario, formó parte de una construcción discursiva e ideológica que, durante los primeros años de existencia del franquismo, bramó con contundencia contra todo lo que distorsionase el sobrio esplendor de una nación que resurgía con la victoria. Si bien este desvío podía producirse a través de la pasividad, la indolencia o la fofez en las que cualquier fuerza o ímpetu se desvanecían, en lo tocante a celebraciones como las Fallas, la preocupación fue que el exceso impidiese la conversión del colorín en color y que la amenaza de esa otra versión de una nación pervertida pusiera en peligro la afirmación de la virilidad de la nueva España franquista.

91. Ricardo, Juan: "Elogio del buñuelo y de la buñolera", Libro Fallero, 14-19 de marzo de 1940.

92. Una visión de conjunto del anticasticismo, en Box, Zira: "La mirada sobre Madrid: anticasticismo y castellanismo en el discurso falangista radical de la inmediata posguerra», Historia y Politica, 27, 2012, pp. $143-166$. 